\section{Atuação de religiosos}

\section{luteranos nos}

\section{movimentos}

\section{sociais rurais}

no Brasil

\section{(1975-1985)}

\section{Fábio Py[*]}

\section{Marcos Antonio Pedlowski[**]}

[*] Programa de Pós-graduação em Políticas Sociais (PGPS) da Universidade Estadual Norte Fluminense Darcy Ribeiro (Uenf) - Campos dos Goytacazes (RJ) - Brasil.

E-mail:pymurta@gmail.com

ORCID: https://orcid.org/0000-0002-7634-8615

[**] Programa de Pós-graduação em Políticas Sociais (PGPS) da Universidade Estadual Norte Fluminense Darcy Ribeiro (Uenf) - Campos dos Goytacazes (RJ) - Brasil.

E-mail: pedlowma@uenf.br

ORCID: https://orcid.org/0000-0003-3949-8240
Resumo: O presente artigo tem o objetivo de discutir a atuação de segmentos luteranos na construção e no desenvolvimento dos movimentos sociais rurais do Sul do Brasil, particularmente no processo de formação do Movimento dos Trabalhadores Rurais Sem Terra (MST). Esse esforço visa a demonstrar que os luteranos ajudaram na construção da relação entre prática e reflexão mediante ações culturais, educativas e organizativas no interior dos movimentos sociais rurais. Para traçar tal atuação, foram destacados três religiosos luteranos que tiveram função ativa junto aos camponeses: Gernote Kirinus, Werner Fuchs e Milton Schwantes, que desenvolveram trajetórias individuais dissonantes da ênfase da estrutura religiosa luterana no Brasil.

Palavras-chave: CPT; MST; Teologia da Libertação; luteranos; justiça no campo.

Performance of Lutheran religius in rural social movements in Brazil (1975-1985)

\begin{abstract}
The goal of this article is to discuss the role of Lutheran segments in the construction and development of rural social movements in Southern Brazil, particularly in the process of formation of the Landless Rural Workers Movement (MST). This effort aims at demonstrating that Lutherans helped to build the relationship between practice and reflection through cultural, educational and organizational actions within rural social movements. Three Lutheran religious intelectuals who had an active role with the peasantry were identified: Gernote Kirinus, Werner Fuchs and Milton Schwantes, who developed individual dissonant trajectories to the emphasis of the Lutheran religious structure in Brazil.
\end{abstract}

Keywords: CPT; MST; Liberation Theology; Lutherans; justice in the countryside. 


\section{Introdução}

$\mathrm{E}$ ste artigo tem o objetivo de descrever a participação de luteranos na organização dos movimentos sociais rurais no Brasil, ao mesmo tempo que se propõe discutir a luta pela terra no Brasil contemporâneo. O período delimitado vai de 1975 e 1985, aquele no qual a participação de pastores protestantes ${ }^{1}$ na tentativa de desarticulação da estrutura fundiária brasileira baseada no "latifúndio improdutivo" ocorreu de maneira mais contundente. O ponto de partida é uma reflexão sobre fatos ocorridos no ano 1975 , uma vez que nele ocorreu o encontro convocado pela Confederação Nacional dos Bispos do Brasil (CNBB) que resultou na fundação da Comissão Pastoral da Terra (CPT). Desde a sua criação, a CPT passou a exercer um importante papel na articulação de diversas experiências de organização das lutas sociais no campo. Quanto ao ano 1985, foi escolhido como limite para as análises realizadas no artigo, pois, além de ser o marco do processo de redemocratização, este ano ficou marcado pelo anúncio pelo governo José Sarney (19851990) do Plano Nacional de Reforma Agrária (PNRA). ${ }^{2}$ Além disso, é importante notar que, embora tenha sido anunciado no final da ditadura civil-militar, o PNRA foi baseado naquele que foi um dos primeiros atos legais tecidos pelo regime militar de 1964, Estatuto da Terra, ${ }^{3}$ promulgado por meio da Lei no 4.504, de 30 de novembro de 1964.

A questão agrária e a organização dos movimentos sociais rurais ganharam importantes contornos no cenário brasileiro do pós-Segunda Guerra Mundial. Cabe aqui apontar que as Ligas Camponesas, movimento atuante na luta pela terra no Brasil entre as décadas de 1950 e 1960, são consideradas por Stédile (2006, p. 34-37), Roseli Caldart (2000, p. 132-135) e Domingues (2005, p. 45-48) como precursoras do Movimento dos Trabalhadores Rurais Sem Terra (MST). Para Stédile e Domingues, as Ligas Camponesas, assim como a CPT, as Comunidades Eclesiais de Base (CEBs), ${ }^{4}$ o Movimento Justiça e Terra (MJT) e o Movimento

\footnotetext{
O movimento protestante no Brasil apresenta-se dividido em duas "fases". A primeira compreende o chamado "protestante de imigração", definido como aquele que chega ao Brasil entre os anos 1830 e 1930 com o objetivo de habitar o Brasil imigrando, em grande parte, de países como Alemanha, Polônia, Rússia e Inglaterra. O segundo tipo foi chamado classicamente de protestantismo "histórico" ou "de missão". Vindo do sul dos Estados Unidos, chega ao Brasil com o intuito de evangelização (Py, 2016a, p. 43-58).

${ }^{2}$ O PNRA teve início no governo Sarney, visando a representar as organizações sociais rurais, entre elas a Confederação Nacional dos Trabalhadores na Agricultura (Contag) e o MST. Anunciado pelo governo no IV Congresso Nacional dos Trabalhadores Rurais, o PNRA consistia em um plano de reforma agrária que visava a assentar 7,1 milhões de trabalhadores em 15 anos.

${ }^{3}$ O MST, em seu Primeiro Congresso Nacional dos Sem-Terra, em 1984, fez críticas ao Estatuto da Terra, indicando que com ele colocava-se a solução para o campo na empresa rural, favorecendo a exploração do trabalhador. Por isso, - Movimento investiu em ocupações para reivindicar o que se defendia, por exemplo, na Contag. Para uma melhor análise da Contag, ver Ramos (2010, p. 1-21).

${ }^{4}$ As CEBs surgiram na década de 1960, no Brasil, com as seguintes características: 1) são de comunidades ligadas à fé cristã; 2) encontram-se em pequenos locais; 3) organizam-se pelos leigos; 4) têm liberdade litúrgica; 5) são incentivadas pelo Concilio Vaticano II e pela nova articulação da Igreja na América Latina.
} 
dos Agricultores Sem Terra do Oeste (Mastro) formam um "conjunto" de movimentos sociais rurais que permitiram a formação dos Sem- Terra. $^{5}$

Por outro lado, Mendonça (1986, p. 33-36) argumenta que a formação desse "conjunto" de movimentos sociais do campo ocorreu influenciada pelo processo de industrialização no campo. Esse processo pode ser relacionado com o ajustamento da economia brasileira à política de substituição das importações, que vinha ocorrendo desde a República Velha e que se aprofundou no período pós-1930 (Tabela l).

Tabela 1. Indicadores de modificações estruturais da economia brasileira

\begin{tabular}{|l|l|l|l|}
\hline \multicolumn{4}{|c|}{ Estrutura do produto físico (a preços correntes) (\%) } \\
\hline & 1907 & 1919 & 1939 \\
\hline Agricultura & 79 & 79 & 57 \\
\hline Indústria & 21 & 21 & 43 \\
\hline \multicolumn{4}{|c|}{ Taxas anuais de crescimento (\%) } \\
\hline & Agricultura & Indústria & Total \\
\hline $1920-1929$ & 4,1 & 2,8 & 3,9 \\
\hline $1933-1939$ & 1,7 & 11,2 & 4,9 \\
\hline $1939-1945$ & 1,7 & 5,4 & 3,2 \\
\hline
\end{tabular}

A partir da análise desses dados, é possível verificar o valor que a industrialização adquiriu no século XX, principalmente, durante a Era Vargas (1930-1945), e a falta de incentivos estatais aos camponeses em meio a péssimas condições de vida que ocorriam no campo no Brasil. A partir dos anos 1950 e 1960, a ação econômica sobre o meio rural organizou-se, gerando o desenvolvimento econômico baseado nos seguintes elementos: 1) liberação de mão de obra a ser utilizada no setor industrial; 2) mecanização das lavouras, aumentando a quantidade de alimentos; 3) criação de mercado para os produtos da indústria; e 4) expansão das exportações. Esses pontos ampliaram a desigualdade na estrutura rural brasileira (Py, 2016a, p. 34-57; Fernandes, 2000, p. 49-60).

${ }^{5}$ Rosilene Caldart estabelece uma distinção entre Sem-Terra e sem terra. Para a autora, Sem-Terra, com hífen e letra maiúscula, configura-se como um nome próprio, fruto da identidade política construída a partir da autonomia de algumas massas e da organização social. Já a nomenclatura sem terra é um substantivo de dois gêneros e dois números, que responde a um indivíduo do meio rural sem propriedade e sem trabalho, que não tem uma marca de movimento. Para Caldart, o uso da terminologia, hoje, modificou a flexão do número, até porque o mais comum é a designação sem terra (Caldart, 2000, p. 17-18). 


\section{Antecedentes da CPT e do MST: movimentos messiânicos, as Ligas Camponesas e a luta pela reforma agrária}

Na história do Brasil, destaca-se a relação dos movimentos e das revoltas com os tons religiosos em prol da luta pela terra. Por exemplo, no Segundo Reinado ocorreu no Rio Grande do Sul um movimento desembocado na Revolta dos Muckers (1868), liderado por Jacobina Mentz, em Sapiranga. Em seu carisma, conjugava elementos messiânicos, chegando a ser reconhecida como Jesus Cristo, levando ao massacre de seus liderados pelo exército em 1874 (Giumbelli, 1997, p. 67-69). Pouco depois eclodiu na Bahia a organização de Canudos, levado por Antonio Conselheiro, outro líder religioso-social, em que se defendia a monarquia contra a república que surgia. O movimento de Canudos se firmou com base na luta por terra, logo contrário aos latifundiários, a fome e a miséria do Nordeste. Como a Revolta dos Muckers, foi massacrado em 1897 (Giumbelli, 1997, p. 67-69).

Em 1912, entre Santa Catarina e o Paraná, mediante a entrega de terras do governo às companhias madeireiras estrangeiras, inflamara-se os camponeses a contestar a decisão junto aos governos estaduais e ao federal. Assim nasceu o movimento do Contestado, formado por imigrantes defendendo a volta do Império (1912), liderados pelo monge Jose Maria de Santo Agostinho. O monge carregou religiosamente o conflito quando declarou "guerra santa" às tropas federais, resistindo a elas por quatro anos. Mesmo com sua morte, seus seguidores continuaram lutando, energizados pela "esperança messiânica" de nova vida (Giumbelli, 1997, p. 67-69). Finalmente, nesse pequeno histórico dos movimentos messiânicos, no Ceará, na década de 1930, o beato José Lourenço organizou o movimento do Caldeirão de Santa Cruz no semiárido, na cidade de Crato, criando uma comunidade igualitária, baseada no trabalho e no cristianismo, protegida pelo Padre Cícero — outro movimento reprimido pelo governo federal (Giumbelli, 1997, p. 67-69).

Deixando o contexto dos movimentos messiânicos entre o século XIX e o inicio do século XX. No meio do século XX, diante da drástica desigualdade social no campo da década de 1950, brotaram as Ligas Camponesas de Pernambuco, cujo objetivo era avançar a luta pela reforma agrária, com a liderança do deputado e advogado Francisco Julião. Em função de seu forte papel na organização na realização de mobilizações em larga escala no Brasil, as Ligas Camponesas de Pernambuco acabaram sendo duramente perseguidas e desarticuladas pelo regime militar de 1964. Nesse sentido, é possível afirmar que, no período anterior à ditadura militar, agravaram-se os problemas sociais, com aprofundamento do processo de concentração de renda, intensificando-se a questão fundiária (Mendonça, 2006, p. 67-69; Fernandes, 2000, p. 49-60). Fruto dessa problemática, as lutas camponesas se alastraram por todo o país. Em resposta, o governo militar promoveu a criminalização da luta pela reforma agrária entre 1954 e 1964 (Fernandes, 2000, p. 49-60). 
Antes do MST, as Ligas Camponesas foram o movimento social que nasceu das lutas dos pequenos agricultores e não proprietários contra a tentativa de expulsão das terras onde trabalhavam, principalmente entre 1954 a 1962, alastrando-se por todo o Nordeste (Page, 1989, p. 18-19). As Ligas eram, assim, um braço de luta contra a "indústria da seca" no Nordeste, ela, que foi o modus operandi dos grandes proprietários de terra, que transformavam a seca em "negócio, e como os açudes construídos com verbas públicas para o benefício de toda uma população rural acabavam servindo a uns poucos latifundiários" (Motta e Esteves, 2009, p. 246).

Como se disse, o ano 1954 é o marco inicial das Ligas Camponesas de Pernambuco em função da luta dos moradores do Engenho Galileia, do latifundiário Oscar Beltrão, localizado no município de Vitória de Santo Antão, em Pernambuco. No âmbito dessa disputa, Oscar Beltrão pressionou os militares, e os camponeses estrategicamente mobilizaram "as forças progressistas da capital, com vista a trazer a público a repressão a que estavam sendo submetidos os foreiros de Galileia”; assim nasceu, entre a "capital e dos contatos com políticos e personalidades que se propuseram a apoiar os camponeses da Galileia, o embrião das Ligas Camponesas do Brasil" (Motta e Esteves, 2009, p. 243-257). Nesse processo, Francisco Julião se uniu à causa das Ligas, conseguindo, em 1956, vencer o processo judicial que deu posse das terras do engenho da Galileia para os agricultores organizados (Rollemberg, 2001, p. 51).

Já em 1961, Francisco Julião abriu um canal de diálogo com o líder comunista Luís Carlos Prestes para unir as forças do Partido Comunista Brasileiro (PCB) com as das Ligas Camponesas. Em função disso, Prestes sugeriu a fusão das Ligas com a União dos Lavradores e Trabalhadores Agrícolas do Brasil (Ultab), fundada pelo PCB em 1954 e que tinha um programa de melhoria das condições de vida dos trabalhadores agrícolas (Rollemberg, 2001, p. 5l-54). No entanto, as Ligas representadas por Francisco Julião pediam a realização de uma reforma agrária radical, o que terminou por estabelecer um impasse político que impediu que um acordo fosse firmado. Em 1962, a força das Ligas Camponesas de Pernambuco começou a decrescer, enquadrando institucionalmente o movimento camponês pelo governo federal e pelo assassinato do amigo de Francisco Julião, Pedro Teixeira (Rollemberg, 2001, p. 58-61).

Não se pode deixar de destacar que, além das Ligas Camponesas de Pernambuco, houve as Ligas Camponesas da Paraíba, na região da Zona da Mata. Formaram-se sobre impactos do monopólio fundiário, monocultura e exploração do trabalho. A primeira Liga na Paraíba foi a de Sapé, liderada por João Pedro Teixeira, que tivera contato com o PCB mediante seu trabalho nas pedreiras em Recife. Organizou-se por conta da exploração na área da cana-deaçúcar com sua primeira reunião ocorrida em 1955, também com a presença de Pedro Inácio de Araujo e João Alfredo Dias (Targino, Moreira e Menezes, 2011, p. 83-117).

Depois, João Pedro Teixeira foi preso e espancado a mando dos latifundiários. A partir disso, foram três anos de trabalho de bases, de convencimento e, em 1958, fundou-se a Liga Camponesa do Sapé em cartório. A figura de João Pedro Teixeira mobilizou agricultores, 
e assim Sapé passou a ser o berço do movimento camponês da Paraíba, tanto que, em 1961, pelo rápido desenvolvimento, formalizou-se a criação da Federação dos Lavradores e Trabalhadores Agrícolas da Paraíba — chamada de Federação das Ligas Camponesas da Paraíba. As Ligas paraibanas promoviam: comícios e passeatas, apoio de trabalhadores expulsos das propriedades, assistência jurídica aos camponeses, serviço de saúde, combate ao analfabetismo e luta pela reforma agrária. Foram brutalmente reprimidas a partir do golpe militar de 1964 (Targino, Moreira e Menezes, 2011, p. 83-117).

Enfim, como se escreveu, não só as Ligas da Paraíba, mas o desembocar no golpe militar de 1964 teve consequência direta na perseguição e no assassinato de importantes lideranças de ambas as Ligas Camponesas e da Ultab, provocando um forte retrocesso na organização política dos camponeses e colocando a demanda pela reforma agrária em um processo de paralisia (Fontes, 2010, p. 56-59).

\section{A Comissão Pastoral da Terra e sua importância na organização da luta pela democratização da propriedade da terra}

Já na década de 1970, a Igreja Católica, a partir da liderança de d. Pedro Casaldáliga e de d. Tomás Balduíno, redigiu uma série de documentos que apontavam os excessos praticados pelo regime militar (Lowy, 2000, p. 156-161; Domingues, 2005, p. 169-180). Os documentos indicavam ainda os dados da recessão econômica no setor agrário, o que pode ser compreendido nas campanhas da CNBB: "Eu ouvi os clamores do meu povo" (1973); "Marginalização de um povo: grito das Igrejas" (1973); "Comunicação pastoral ao povo de Deus" (1976); "Exigências cristãs de uma ordem política” (1977). Nesse período de forte repressão da ditadura civilmilitar, destaca-se que alguns membros da própria Igreja Católica foram perseguidos e torturados pela polícia política, levando as pastorais à promoção humana (Lowy, 2000, p. 160-161).

Em relação às políticas agrárias do período da ditadura, Fernandes e Stédile (2005, p. 45-48) afirmam que os militares, para manter o domínio sobre o campo, optaram por se aliar aos grandes latifundiários. Um instrumento importante para o regime militar manter esse controle foi a Confederação Nacional dos Trabalhadores na Agricultura (Contag) (Motta e Esteves, 2009, p. 243-257), que havia sido criada ainda no governo do presidente João Goulart. A Contag sofreu, no período ditatorial, a interferência do presidente Castelo Branco, que a colocou sob o controle de José Rotta, representante dos círculos operários católicos pró-ditadura. Para Ramos (2010, p. 3), a Contag tinha representantes junto aos setores progressistas da sociedade civil, porém estava submetida à política da ditadura militar e aos interesses norte-americanos, sendo, portanto, uma parte importante do aparato da estrutura sindical oficial no meio rural. 
A contribuição da Contag para o arrefecimento da luta contra a crescente mecanização e exploração no campo acarretou o intenso fluxo de pessoas para as cidades, agravando ainda mais as condições de trabalho no campo (Mendonça, 2006, p. 78-79). Esse quadro ocasionou que, em 22 de junho de 1975, durante o Encontro de Pastoral da Amazônia, organizado pela CNBB, em Goiânia, ocorresse a criação da CPT. O surgimento da CPT em meio à grave situação dos trabalhadores rurais, posseiros e peões fez com que ela se colocasse desde sua fundação contra o regime militar, que claramente representava os interesses capitalistas nacionais e transnacionais (Fernandes e Stédile, 2005, p. 67-69; Fernandes, 2000, p. 34-36). A CPT passou a auxiliar paróquias de comunidades rurais por meio da interação com as CEBs, visando a romper o isolamento do campo, tendo a preocupação de contribuir para a

[...] articulação das diferentes experiências que construíram novas formas de organização do campesinato. O trabalho da pastoral da Igreja Católica e Luterana foi fundamental para o processo de reorganização dos trabalhadores do campo [...] foi uma das expressões do trabalho ideológico realizado pela Igreja Católica, que teve um papel essencial para o redimensionamento político da luta pela terra em todas as regiões do país, alertando para a necessidade da construção de um movimento nacional. Este trabalho ideológico da CPT foi fruto de um processo de autocrítica vivenciado pela Igreja Católica, principalmente na América Latina. (Carvalhães e Py, 2018, p.342).

Como afirmam Fernandes e Stédile, (2005, p. 45-48), a CPT era uma instância religiosa que atuava na organização dos movimentos sociais rurais durante o regime militar. Dentre as muitas ações realizadas por ela durante o regime militar, merece destaque o apoio dado aos movimentos de luta dos camponeses desapropriados para a construção da hidrelétrica de Itaipu. Além disso, na região oeste do Paraná (e em outras partes do Sul do Brasil), as CEBs foram desenvolvidas com a maioria de protestantes luteranos (por causa da imigração germânica na região), sendo nelas promovidas assessorias, cursos, formação de jovens e camponeses para que desenvolvessem a capacidade de analisar a organicidade da realidade social brasileira (Fucks, 2002, p. 56-61). Por essa característica, em certas regiões alguns pastores luteranos assumiram cargos junto à CPT. Gernote Kirinus, Werner Fucks, Inácio Lemke e Sergio Sauer, por exemplo, chegaram a ocupar cargos regionais ou até mesmo nacionais. Tal fato demonstra que a CPT historicamente mantém uma trajetória ecumênica e de diálogo, mesmo pertencendo a um setor tão dorsal do catolicismo brasileiro como a CNBB.

No entanto, não se pode deixar de destacar os conflitos internos que a opção ecumênica ocasionou. Destaca-se como exemplo a retirada do pastor Inácio Lemke do cargo de vicediretor nacional em 1985, retornando ao cargo somente em 1987 (Fucks, 2002, p. 61-64). 


\section{A organização do campo a partir da constituição da CPT e do MST com a contribuição dos luteranos}

Embora os conflitos existissem, pode-se afirmar que a CPT, desde a sua formação, sempre buscou nutrir o ecumenismo, ou, como escreve Werner Fucks, "um ecumenismo de bases" (Fucks, 2002, p. 65). Foi por essa vontade do "ecumenismo desde as bases" (Fucks, 2002, p. 67) que a direção nacional contou, desde o seu nascedouro, com a presença de lideranças luteranas em suas reuniões, principalmente com religiosos da Igreja Evangélica da Confissão Luterana no Brasil (IECLB) - como afirmam Fernandes e Stédile (2005, p. 76). A IECLB, segundo Gertz (2001, p. 9-33) e Py (2016b, p. 342-356), sempre teve relação direta com o campo brasileiro, pois fora tradição religiosa da maioria dos germânicos que migraram para o país desde o Novecentos, contribuindo de forma direta para a organização da luta camponesa pela terra.

Uma das principais diretrizes que norteavam as ações da CPT era que os pequenos agricultores deveriam participar de ocupações de terras, fazendo pressão para que a discussão sobre a questão do grande latifúndio improdutivo fosse feita. Internamente, a ocupação das terras era incentivada pela CPT desde o ano 1981, quando ocorreu a ocupação da Fazenda Macali, próxima da Encruzilhada Natalino, localizada no Rio Grande do Sul, vizinha ao município de Ronda Alta, cuja transformação em assentamento de reforma agrária ocorreria três anos mais tarde. O sucesso da ocupação da Fazenda Macali estimularia ocupações realizadas pelos sem terra (Fernandes, 2000, p. 49-60).

Outra grande ocupação, ainda no governo Figueiredo, ocorreu em 1984, quando, dentro da CPT, foi organizada a tomada da Fazenda Annoni no norte do Rio Grande do Sul, entre os municípios de Pontão e Sarandi (Benincá, 1987, p. 113-119). Essa ocupação foi traçada como uma forma de resposta ao plano econômico aplicado pelo general Figueiredo, apoiado pela Contag (Fernandes, 2000, p. 55). Tal plano vinha deixando a economia brasileira com níveis altos de desemprego e ainda mais expressivos no meio rural (Mendonça, 2006, p. 81-83). Nesse contexto, a Fazenda Annoni foi ocupada por cerca de 7 mil pessoas, a grande maioria vinda de municípios da região do Alto Uruguai, em uma grande demonstração da força da CPT junto ao movimento campesino (Benincá, 1987, p. 119-120). Assim, no dia 11 de fevereiro de 1985, a CPT promoveria, na Fazenda Annoni, a IX Romaria da Terra, com a vinda de milhares de pessoas de cidades gaúchas para a fazenda (Gertz, 2001; Benincá, 1987, p. 119-120), entre elas vários protestantes luteranos, que vieram para a área.

Outra importante instituição na organização dos movimentos rurais no Brasil foi o Partido dos Trabalhadores (PT), que apoiou uma série de assentamentos de agricultores sem terra, como indica Fontes (2010, p. 233-234). Um detalhe para entender tais conflitos, que 
levariam à formação do MST, foram as divergências surgidas entre a CPT e o movimento dos próprios camponeses em relação aos rumos do acampamento da Fazenda Annoni (Benincá, 1987, p. 122-129). Para Caldart (2000, p. 21-258), as divergências deram-se, principalmente, nos objetivos da caminhada de 250 agricultores sem terra da Fazenda Annoni até Porto Alegre no mês de maio de 1985. A CPT desejava uma caminhada pacífica, enquanto os agricultores sem terra pretendiam ações mais radicais, com novas ocupações de fazendas para forçar desapropriações (Caldart, 2000, p. 34-36; Benincá, 1987, p. 122-132).

Assim, surge o MST, resultado dos embates entre as direções da CPT e as lideranças dos sem terra no acampamento da Fazenda Annoni, o que determinou o afastamento das lideranças católicas do papel dirigente da luta pela terra, que então estava concentrada no Rio Grande do Sul. O MST passou a ter seu próprio programa de formação política, deixando de lado o vínculo mais direto com a Igreja. Por sua vez, os membros da Igreja se afastaram justamente para possibilitar uma maior liberdade de organização e ação dos trabalhadores sem-terra, como escreve Fernandes (2000, p. 49-60).

Mesmo com o afastamento das lideranças da Igreja Católica, é possível destacar atividades de luteranos como Leonildo Gaede, Roberto Zwesth, Silvio Meinke, Carlos Arthur Dreher, Milton Schwantes e Gunter Wolff — que estiveram envolvidos direta e indiretamente nas ações de politização do campo (Py, 2016b, p. 342-356). Esses luteranos atuavam na organização camponesa principalmente nas década de 1980 e 1990, momento no qual ocorreu um aumento nos níveis da concentração fundiária, na mecanização das lavouras e no desemprego rural no Brasil (Fernandes e Stédile, 2005, p. 45-48).

Entre 1975 e 1982, foi notável a atuação de Gernote Kirinus e de Werner Fuchs entre os camponeses que estavam envolvidos no processo de "gestação"6 do MST. As atividades de Kirinus e Fuchs se estendiam desde cursos de formação política a assessorias, mas também a discussões que ocorreram nos acampamentos da Fazenda Annoni, especialmente debates sobre reforma agrária. Os luteranos, desde o início do acampamento da Fazenda Annoni, atuaram como intelectuais ligados à práxis, dando apoio aos agricultores acampados, não se vinculando somente à CPT, mas também ao MST. Os religiosos luteranos marcaram presença nos debates e nas reuniões que levaram à oficialização do MST, como aponta Fernandes (2000, p. 49-60). Por outro lado, os luteranos participaram do Primeiro Congresso Nacional dos Sem Terra (PCNST), formando a plataforma ideológica do movimento na luta contra o "latifúndio improdutivo". Além disso, uniram forças para ajudar a unificar o MST desde o Sul do Brasil, no Nordeste e na Amazônia, tendo como ponto de partida o entendimento de

${ }^{6}$ Aqui se considera a "gestação do MST" entre as datas de 1975 a 1984, termo utilizado de Bernardo Mançano Fernandes na obra A formação do MST no Brasil (2000, p. 49-60). 
que a ocupação da terra era uma forma de resistência legítima da luta camponesa pela terra (Caldart, 2000, p. 34-36; Benincá, 1987, p. 122-132).

Portanto, é possível afirmar que, a partir da CPT, a Igreja Católica teve grande importância na formação do MST. Contudo, também é correto observar que houve participação direta de intelectuais protestantes, entre eles luteranos da IECLB, no processo de organização da resistência política dos camponeses (Py, 2016b, p. 342356). E, como já apontado anteriormente, também na ocupação das Fazendas Macali e Annoni e na organização do PCNST (Benincá, 1987, p. 122-132). Um legado já visto anteriormente no luteranismo pela atuação de Gernote Kirinus, Werner Fuchs, ligados à CPT (1975-1982), e Leonildo Gaede, Silvio Meinke, Milton Schwantes e Gunter Wolff, a partir de 1984, nos acampamentos pré-MST, com destaque para a organização na luta pela terra e contra grileiros e latifundiários.

A relação do luteranismo com os movimentos sociais rurais entre 1975 e 1985 pode ser verificada nos arquivos sinodais luteranos, no Manifesto de Curitiba, nas atas da Comissão Pastoral da Terra, nos boletins, os quais apontam o vínculo do "cooperativismo" luterano, como demonstra a tese de Vanderlinde (2004, p. 310-335), tendo sido construtor dos movimentos sociais rurais, e especificamente do MST (Py, 2016b, p. 342-356; Fernandes e Stédile, 2005, p. 45-48), em que tiveram papel importante na construção de sua plataforma ideológica.

\section{Os luteranos e a gestação do MST}

Como se vem apontando, algumas lideranças religiosas luteranas desempenharam papel importante na organização dos movimentos rurais na luta pela terra no período entre 1975 e 1985 (Py, 2016b, p. 342-356; Fernandes e Stédile, 2005, p. 45-48). Desse modo, é importante detalhar a contribuição dos religiosos luteranos para a luta pela reforma agrária no Brasil no período final da ditadura militar brasileira. Nesse contexto, é igualmente importante salientar que a atuação dos luteranos no Brasil, a partir da década de 1960, estava embasada na Teologia da Libertação de matriz protestante, influenciada pela chamada "Teologia da Revolução”, do teólogo presbiteriano Richard Shaull, ’ a qual foi difundida, no Brasil, pelo

\footnotetext{
Millard Richard Shaull (1919-2002) foi um teólogo presbiteriano ecumênico estadunidense, reconhecido por suas contribuições ao desenvolvimento da gênese da Teologia da Libertação latino-americana. Atuando como missionário na América Latina (notadamente na Colômbia e no Brasil), desenvolveu um pensamento teológico profundamente marcado pela centralidade de temáticas políticas e sociais características do contexto latino-americano, voltando-se para a análise das relações entre religião e sociedade, fé e política. Sua reflexão teológica tem sido constantemente associada ao desenvolvimento da assim chamada "Teologia da Revolução", que alcançou um status no cenário teológico internacional, sobretudo a partir da Conferência Mundial sobre Igreja e Sociedade, realizada em Genebra, em 1966, sob os auspícios do Conselho Mundial de Igrejas (CMI). Shaull desenvolveu um método teológico marcado pela correlação constante entre a mensagem cristã e a situação humana.
} 
corpo docente do seminário teológico de São Leopoldo (Dreher, 1984, p. 38-43). A aplicação dos preceitos emanados dos ensinamentos de Shaull levou a que o luteranismo produzisse seus primeiros "teólogos da libertação".

Na década seguinte, pelo recrudescimento do regime militar durante o governo Médici (1968-1973) e pelo aprofundamento da repressão, sobretudo no meio rural, luteranos ligados à Teologia da Libertação, por meio do documento Carta de Curitiba, ${ }^{8}$ escrita em 1970, passaram a denunciar o processo de expropriação no campo brasileiro e no aprofundamento da estrutura latifundiária improdutiva. Por meio desse manifesto, pastores luteranos, como Leonildo Gaede, Roberto Zwesth, Silvio Meinke, Carlos Arthur Dreher, Milton Schwantes e Gunter Wolff, passaram a se envolver diretamente nos conflitos rurais no Brasil. E, partir daí, esses religiosos contribuíram de forma decisiva para a consolidação da CPT nos setores camponeses dos Sul (Py, 2016b, p. 342-356).

Nesse momento, religiosos luteranos, como Gernote Kirinus e Werner Fuchs, a partir de suas inserções no Movimento Justiça e Terra (MJS) e no Movimento dos Agricultores Sem Terra do Oeste (Mastro) — que mais tarde se fundiriam no MST —, passaram a participar da organização e da mobilização dos desabrigados pela construção da barragem da hidrelétrica de Itaipu. Em outubro de 1982, Kirinus e Fuchs ajudaram a organizar o chamado "Concílio da Terra", quando segmentos luteranos se posicionaram oficialmente contra o latifúndio improdutivo. O tema do "Concilio da Terra" foi "Terra de Deus — terra para todos", inserindo o chamariz da Igreja Luterana na questão da busca da reforma agrária. No Concílio da Terra, afirmou-se o direito universal pela terra e a defesa da supressão da propriedade privada dos latifúndios (Vanderlinde, 2004, p. 310-335).

No ano 1985, com a retirada da CPT de algumas ações na região Sul, os religiosos luteranos passaram a ter uma atuação mais destacada junto aos acampados, ajudando na formação do MST (Benincá, 1987, p. 122-132). Atuando principalmente na fazenda Annoni, Kirinus e Fuchs passaram a levar para os camponeses assentados, quando da realização do I Congresso Nacional Sem Terra, discursos, palestras e periódicos que ajudaram na formação Sem-Terra. A forte presença de luteranos na fazenda Annoni pode ser constatada a partir da Tabela 2, retirada da dissertação de Benincá (1987, p. 65), que aponta a relação percentual dos diferentes grupos religiosos presentes no acampamento da fazenda Annoni em outubro de 1985.

\footnotetext{
${ }^{8}$ Segundo Tarcísio Vanderlinde (2004, p. 310-335), "trata-se de um documento emblemático, de significado ímpar. emitido pela VII Assembleia Geral do IECBL, em outubro de 1970, na cidade de Curitiba, sendo em seguido entregue pessoalmente ao Presidente da República, General Emílio Garrastazu Médici. O documento apresenta teses sobre as relações entre a Igreja e o Estado e assuntos que preocupam a Igreja. Entre esses, destaca-se o caráter do culto cristão, o ensino cristão [...] e a questão dos direitos humanos".
} 
Tabela 2. Grupos religiosos presentes na fazenda Annoni em outubro de 1985.

\begin{tabular}{|c|c|}
\hline Religião & $(\%)$ \\
\hline Católicos & 21,3 \\
\hline Luteranos & 42,8 \\
\hline Religiões espíritas & 4,1 \\
\hline Religiões "negras" & 0,8 \\
\hline Não adeptos & 31,2 \\
\hline
\end{tabular}

\section{Intelectuais orgânicos luteranos e a questão da terra: Gernote Kirinus e Werner Fuchs}

Para destacar: religiosos luteranos como intelectuais ligados à práxis social, ou, na linguagem gramsciana, "intelectuais orgânicos", assumindo que foram sujeitos diretamente ligados a uma classe social, responsabilizando-se pela construção do projeto da classe a que se vincularam (ou atuando junto aos movimentos sociais). O que se justifica quando se sabe que os pastores Gernote Kirinus e Werner Fucks tiveram uma formação densa em quatro línguas (português, alemão, inglês e espanhol), sendo alfabetizados por meio dos clássicos das humanidades, como Hölderlin, Schelling, Goethe, Schiller, Novalis. A formação estudantil densa humanista era modelo desde os colégios até a formação superior em teologia entre os luteranos. Assim, apoiamo-nos na categoria de Antonio Gramsci, pois desenvolviam a atividade intelectual na prática, ajudando na "homogeneidade e consciência da própria função, não apenas no campo econômico, mas também no campo social e político [...] são, na maioria dos casos, 'especializações' de aspectos parciais da atividade primitiva do tipo social novo que a nova classe deu à luz” (Gramsci, 1982, p. 36).

Compreende-se isso quando se focaliza o trabalho realizado do Gernote Kirinus desde 1975, próximo à formação da CPT (Fucks, 2002, p. 65). Assim, o pastor Gernote Kirinus é uma figura importante para as primeiras lutas da CPT, tendo sido eleito e instalado, em 1977 , como secretário regional da CPT no Paraná, incentivando, a partir da leitura de fragmentos bíblicos, a reflexão sobre a situação do camponês desagregado da terra pela política do Estado brasileiro. Como fonte para verificar essa hipótese, é possível utilizar um fragmento de reflexão do ano 1976 (Ribeiro, 2006, p. 35-40), de uma das reuniões da CPT junto aos agricultores, em que Kirinus destacava que: "O próprio camponês, refletindo sobre a sua realidade à luz do Evangelho, começa a descobrir o seu Estado de opressão, as injustiças de que é vitima, e começa, a partir daí, a organizar sua luta para se livrar desse jugo" (Ribeiro, 2006, p. 35-40).Pouco depois, mediante sua atuação junto a setores camponeses do Alto 
Uruguai, Kirinus foi eleito deputado estadual pelo Partido do Movimento Democrático Brasileiro (PMDB). No cumprimento de seu mandato, notabilizou-se por se posicionar a favor dos pequenos agricultores que estavam passando pelo processo de desapropriação para a construção da usina hidrelétrica de Itaipu. Em um de seus pronunciamentos sobre o que estava ocorrendo na região, afirmou que:

São, além de injustos, irreais, e o que é mais grave, às vezes até alterando a própria realidade jurídica, ao invés de propor indenização, propunha simplesmente um contrato de compra e venda, que vinha causando problemas gravíssimos, sendo que o sistema impedia o agricultor de amanhã ou depois questionar um valor mais adequado. (Ribeiro, 2006, p. 35-40).

Em um famoso pronunciamento, realizado em 27 de maio de 1980, na Assembleia Legislativa do Paraná, chamado "Itaipu: pedra que canta", Kirinus questionou os contratos e a forma com que vinham ocorrendo na desapropriação das famílias que viviam nas áreas que seriam inundadas pelo reservatório da hidrelétrica de Itaipu. Também participou da organização dos agricultores que estavam sendo despejados, sendo um dos fundadores do MJT, que buscava condições de reparação para as 6 mil famílias rurais que estavam sendo desapropriadas.

Por meio das assessorias prestadas por Kirinus junto aos animadores rurais ligados à CPT e formando o MJT, os agricultores elaboraram documentos que tiveram repercussão na imprensa nacional e internacional, como uma carta entregue ao então presidente Ernesto Geisel (1974-1979) quando de sua visita à região. Além de ajudar na organização, Kirinus produziu o periódico Poeira, que indicava às CEBs os trabalhos da CPT (Ribeiro, 2006, p. 66). Essa revista se opunha ao periódico oficial Unicom, produzido pela empresa responsável pela construção de Itaipu e que indicava que não existiam quaisquer dificuldades na região para a realização da obra.

Pelos trabalhos de organização dos agricultores desocupados por Itaipu, pela densa formação escolar ajudando na tecedura do material produzido, Gernote Kirinus é entendido, segundo nossa hipótese e de acordo com a acepção gramsciana, como um intelectual orgânico. Pois sua produção teórica e também sua ação política atuavam no sentido de defender os interesses dos agricultores e trabalhadores rurais, que, segundo Ribeiro (2006, p. 66), tendo como "[...] finalidade de tornar estes trabalhadores mais 'livres e conscientes' tinha uma função pedagógica".

Além das atividades de Gernote Kirinus, outro religioso luterano de destaque foi Werner Fuchs, pastor que assumiu a coordenação da CPT do Paraná (CPT-PR) em Cascavel (1976-1979) e que desenvolveu ações que se alastraram por todo o oeste paranaense com os atingidos de Itaipu, posseiros com notas promissórias rurais. Fuchs também ajudou na organização, em fevereiro de 1981, do Movimento dos Trabalhadores Rurais Sem Terra do 
Oeste do Paraná (Mastro), que durou até outubro de 1982. É importante destacar que as ações de Fuchs junto aos grupos de Itaipu vinham desde 1977, quando assumiu o cargo de diretor da CPT (Mattiello e Queluz, 2011, p. 1-11).

Em julho de 1980, as desapropriações para a construção de Itaipu eram noticiadas em todos os grandes jornais brasileiros. Nesse contexto, a participação de Werner Fuchs, como intelectual orgânico envolvido no movimento dos desapropriados de Itaipu, foi bastante significativa. Por conta da CPT, Fuchs atuou primeiro no MJT e depois no Mastro. ${ }^{9}$ Em sua visão, o objetivo da CPT era estar ao lado do povo que sofria e que lutava em torno dos problemas da terra, por isso "não é suficiente estar ao lado do povo nos problemas pessoais, espirituais e evangélicos com programas evangélicos, mas seria preciso defender o povo em todos os aspectos da vida" (Py, 2016b). Junto a Kirinus, Fuchs participou escrevendo e editando o periódico Poeira. Em um dos números do periódico, descreveu a mobilização das pessoas da área de Itaipu da seguinte forma:

O movimento, por ser uma coisa simples, ao contrário dos sindicatos, com seus nomes "feios" ("quorum", "ata", "protocolo", "estatuto"), permite que as pessoas participem de forma mais ativa: no movimento é simples. Tem a comissão, se a comissão não funciona, reúne e nomeia outra. [...] É um negócio muito mais chão, muito mais dinâmico. A briga é no aqui, no agora, se o pessoal não tá a fim outras pessoas entram e assumem. É uma coisa muito mais dinâmica, mais fluida, com isso tem condições de penetrar nas frestas do sistema. [...] então essa diferença foi importante da gente descobrir aqui. (Mezzomo, 2009, p. 76-107).

Assim, as reflexões de Werner Fuchs ajudaram os agricultores a lutar pela terra, o que levou Mezzomo (2009, p. 78-101) a referendar suas atividades como pertinentes a um intelectual orgânico, sendo decisiva sua atuação para a formação e a homogeneização da consciência dos trabalhadores do campo na luta pelo assentamento das famílias desabrigadas. Nesse contexto é que o Mastro se constituiu em um movimento fundamental para a construção do MST.

\section{Intelectuais orgânicos luteranos e a questão da terra: a contribuição de Milton Schwantes}

A partir da década de 1980, com a lenta abertura política estabelecida pelo regime civilmilitar, os movimentos populares puderam superar a repressão e iniciar um processo de reocupação da cena política. Nesse ínterim, em 1984, 4 mil pessoas participam da Fazenda

${ }^{9}$ Para Mazzarollo (2003, p. 110-123), o Mastro é continuação do MJT, quando busca reivindicar detalhes sobre a justiça do campo. 
Annoni, que pertencia ao latifundiário Ernesto Annoni, no Rio Grande do Sul (Benincá, 1987). O acampamento na Fazenda Annoni foi dividido em várias etapas de organização, sendo a primeira de outubro de 1984 a outubro de 1985.

Entre os principais acontecimentos de seu primeiro período, é possível destacar a ação dos políticos, camponeses da região Sul, e de religiosos incentivando que os agricultores não abandonassem a luta pelo ideal da terra. Em resposta às pressões contra o acampamento, no dia $l 1$ de fevereiro, a CPT promoveu a IX Romaria da Terra, realizada na Fazenda Annoni com a participação de milhares de agricultores e pessoas das cidades do norte gaúcho (Benincá, 1987). Nesse período, destaca-se a atividade do religioso luterano Milton Schwantes, a qual foi mapeada no destaque de Jose Luís Dietrich, líder do Centro Ecumênico de Estudos Bíblicos (Cebi), ${ }^{10}$ como de: "[Milton] é um 'intelectual orgânico', que atuou desde a formação dos Sem-Terra, apoiando suas buscas e pleitos no Brasil, por isso, suas vozes foram ouvidas na Fazenda Annoni ainda em 1985, em busca da terra que era de todos" (Cardoso, 2012, p. 56).

De fato, Schwantes se inseriu nas atuações desde o primeiro ano dos Sem-Terra desde a ocupação, ajudando na formação política dos primeiros trabalhadores camponeses com a produção do periódico Palavra na Vida (PNV) do Centro Ecumênico de Estudos Bíblicos (Cebi). Até porque, entre 1984 e 1986, integrou a direção do Cebi, atuando nos acampamentos e produzindo material pedagógico para acampados, não como um intelectual tradicional, mas como um articulador orgânico do movimento dos sem terra. Atuou organicamente, facilitando a formação política contra o latifúndio, e contribuiu para a formação ideológica dos camponeses acampados, tal como destaca o testemunho de Mercedes Brancher pouco depois, em 1985:

[...] em 1985 na Diocese de Chapecó convidamos Milton Schwantes para assessorar a escola de formação dos agentes diocesanos de pastoral. [...] Uma marca inesquecível selada entre nós foi o seu jeito de desenvolver o estudo bíblico sobre o tema "a terra na Bíblia" e que quem inaugura a violência não é o violentado, mas é o violentador [...]. A forma de interpretar a religião no texto bíblico a partir do conflito foi muito significativa na oportunidade, porque vivíamos na região os primeiros conflitos com ocupações de terra. [...] O estudo bíblico ajudou a discernir os tempos presentes e a fortalecer a esperança no apoio à luta das famílias sem terra que haviam na extensão da paróquia [...]. O compromisso da luta pela terra se consolidou, aprofundou e nutriu ações junto às grandes ocupações de Ronda Alta/Fazenda Annoni, no

${ }^{10}$ O Centro Ecumênico de Estudos Bíblicos ou Centro de Estudos Bíblicos (Cebi) é uma instituição que "fala de leitura popular [...] que nasceu em 1978, a partir da necessidade bem concreta, sentida por muita gente havia vários anos, de se articular um serviço que ajudasse o povo das Comunidades Eclesiais de Base, no uso e na interpretação da Bíblia" (Py, 2016b). Então, o Cebi é a instituição que trata da leitura popular da Bíblia, como se é praticada hoje na América Latina. 
Rio Grande do Sul, onde teve origem a atual organização do Movimento dos Sem-Terra. (Cardoso, 2012, p. 56).

Uma de suas primeiras assessorias junto aos assentamentos ocorreu em 1984, quando destacou o "pobre" na Antiguidade como donos de direitos, atualizando diretamente suas críticas ao presente, no qual escamoteia os empobrecidos, tornando-os subumanos. Em outro momento, isto é, em 1986, foi ao assentamento da Fazenda Annoni, representando o Cedi (Centro Ecumênico de Documentação e Informação), facilitando um estudo bíblico sobre o termo "meu povo" no livro do profeta bíblico Miqueias. Nele, relacionou o termo "meu povo" com as camadas mais pobres dos campos de Judá (século VII a.C.). Com a assessoria, resgata que "só a partir da união dos povos dos campos e seus saberes é que se consegue combater ao estado opressor causador da espoliação da terra e da fome" (1982, p. 67). Na atividade, destaca que desde o passado bíblico existiam espoliados, os quais desde o passado se organizavam contra o Estado opressor.

Outra característica da assessoria de Schwantes era que utilizava bordões bíblicos de tal forma que tais bordões se identificavam com o momento vivido pelos trabalhadores rurais assentados. Dois deles que sempre repetia e que viraram títulos de seus livretos da época: "Deus acampa entre nós" e "Deus fala para os camponeses". Na assessoria proposta pelo Centro Ecumênico de Informação e Documentação (Cedi), em 1986, Schwantes expôs o conteúdo de seu texto: "Profecia e Estado: uma proposta para a hermenêutica profética" (Schwantes, 1982, p. 65), que escreveu pouco antes para os agricultores espoliados pelo agronegócio no sul do Paraná. Nela, propõe que os textos de Amós não tratam do "fim total do povo", mas apenas do modus "totalitário", dos Estados opressores, sugadores dos espoliados. Levado pela realidade brasileira, o jovem pastor afirma que a profecia "provém do movimento do campesinato" (Py, 2016b, p. 159), o que estaria em completo "antagonismo ao Estado", que desde a Antiguidade se firma na urgência do "fim do templo e palácio, da cidade-capital e do rei" (Schwantes, 1982, p. 69). No discurso, Schwantes confronta o Estado militar brasileiro em suas relações com as igrejas (católicas, protestantes e evangélicas), também atenuando as conexões exploradoras da cidade com suas monarquias totalitárias ante os produtos plantados nos campos.

No fim do texto "Estado e profecia" (1982), Schwantes diferencia sacerdotes e profetas. Utiliza, para isso, a teoria sociológica da religião weberiana, quando postula que profetas são os que organizam a resistência nos campos e vilarejos junto aos agricultores e camponeses em descontinuidade a seus opressores. Já os sacerdotes não apresentam críticas na direção dos Estados totalitários, mas se beneficiam dos Estados e das lideranças opressoras — seus aliados históricos. Sobre eles, Schwantes diz que "nem brotam perguntas, questionamentos, pelo lugar do Estado dentro da ordem ou das ordens existentes" (Schwantes, 1982, p. 69). 
Se todo historiador do "passado é ao mesmo tempo um historiador do tempo presente", como destaca Braudel (2011, p. 54), o luterano assume que o sacerdócio não denuncia o status quo; ao contrário, aproveita-se pela promulgação dessas instituições. Na sequência, afirma que "não é do templo e nem da estabilidade sacral que provém à contestação [sic] à opressão arregimentada sob estruturas estatais" (Schwantes, 1982, p. 69), mas, sim, a luta, organização que vem de quem originalmente "produz, trabalha" (Schwantes, 1982, p. 69).

Portanto, para ele, eram os trabalhadores do presente (tendo em vista o passado) que deveriam se organizar contra as elites comensais do Estado. Assim, finalmente, Schwantes aponta o local que as igrejas deveriam ocupar ante seu tempo. Entende que elas deveriam estar ligadas à memória do rebelde Jesus Cristo, incentivando o fileiramento junto às organizações populares divergentes ao Estado tributário capitalista. Portanto, assumia a profecia como ponto fulcral de efervescência do cristianismo, ideia que aglutinava os cristãos junto às organizações pastorais camponesas na luta pela dignidade do humano.

\section{Conclusão}

Com a atuação do Milton Schwantes nos acampamentos dos primeiros Sem-Terra, concluímos a equação traçada de religiosos luteranos agindo como componentes significativos do processo de construção da consciência na formação de movimentos sociais rurais. Merece destaque no texto que a CPT, mesmo sendo um organismo da CNBB, permitiu o envolvimento e a ação de religiosos de outras tradições cristãs internamente. Mais até: estrategicamente, em algumas áreas do Sul do Brasil, onde o catolicismo não era tão hegemônico, luteranos da IECLB ligados à Teologia da Libertação exerceram altos cargos. Por exemplo: dois dos pastores aqui descritos ocuparam cargos de liderança no órgão: Gernote Kirinus (na CPT Sul) e Werner Fucks (CPT do Paraná). Já o pastor Inácio Lemke chegou a ser vice-diretor em 1985 da CPT. Como se disse no artigo, esse ecumenismo da CPT tem como centro de gravidade o diálogo religioso, que vai desde suas bases até os documentos estruturais, levando à aglutinação da discussão e prática da luta pela terra, tal como escreve Werner Fucks, rememorando as palavras do próprio d. Pedro Casaldáliga (2002, p. 58): "o maior inimigo é o latifúndio".

Nesse sentido, a CPT é órgão ecumênico da CNBB dedicado à luta pela justiça no campo que teve, além de seus padres, religiosos luteranos fazendo parte do conjunto de intelectuais que ajudaram a construir a plataforma ideológica contra a hegemonia do Estado. Ele, que legitima a propriedade improdutiva, agindo contra determinada fração da classe dominante - a dos grandes proprietários rurais - em prol dos interesses dos deserdados da terra, os camponeses. Nesse caso, como se tematizou, uma parcela de 
religiosos luteranos ajudou na construção e no desenvolvimento de movimentos sociais rurais no Brasil entre 1975 e 1985. E os movimentos sociais rurais nos quais desenvolveram atividades foram o MJT e o Mastro, ambos que mais tarde deram origem ao MST. Esses religiosos atuaram desde diretamente, com prédicas (nos assentamentos e nas CEBs), ou organizativamente, construindo material especializado para reconhecimento das questões do camponês/camponesa.

Para tanto, o presente trabalho flexibiliza certo senso comum tido nos manuais da história da Igreja (Lowy, 2000) e na historiografia sobre o Brasil recente rural (Fernandes e Stédile, 2005; Fernandes, 2000) do vínculo (quase unívoco) do MST com o catolicismo brasileiro, ainda que seja majoritário. Com as descrições, buscou-se demonstrar que ocorreu de forma ativa a intervenção de religiosos luteranos, ao menos na prática organizativa e de reflexão sobre os movimentos sociais tão importantes na contemporaneidade brasileira. 


\section{Referências bibliográficas}

BENINCÁ, Eli. Conflito religioso e práxis: a ação política nos acampamentos de Encruzilhada Natalino e Fazenda Annoni e o conflito religioso. Dissertação (Mestrado em Ciências da Religião) - Instituto de Ciências Humanas, Pontifícia Universidade Católica de São Paulo, São Paulo, 1987. 345f.

BRAUDEL, Fernand. Escritos sobre a história. São Paulo: Perspectiva, 2011.

CALDART, Roseli. Pedagogia do Movimento Sem Terra: escola é mais do que escola. Petrópolis: Vozes, 2000.

CARVALHAES, Claudio; PY, Fábio. Teologia da libertação: nomes, temas e interesses. Crosscurrents, n. 12, p. 334-356, 2018.

CARDOSO, Nancy Cardoso (Org.). Milton Schwantes: escrito de amor e compaixão. São Leopoldo: Cebi, 2012.

DOMINGUES, Eliane. O Movimento dos Trabalhadores Rurais Sem Terra, Contestado e Canudos: algumas reflexões sobre religiosidade. Memorandum, Belo Horizonte, v. 4, p. 169-180, 2005.

DREHER, Martin. Luteranismo e participação política. In: _. Reflexões em torno de Lutero II. São Leopoldo: Sinodal, 1984. p. 121-132.

Milton Schwantes: um perfil biográfico. In: DREHER, Carlos; DREHER, Isolde (Org.). Profecia e esperança: um tributo a Milton Schwantes. São Leopoldo: Oikos, 2006. p. 18-24.

FERNANDES, Bernardo Mançano. A formação do MST no Brasil. Petrópolis: Vozes, 2000.

; STÉDILE, João Pedro. Brava gente: a trajetória do MST e a luta pela terra no Brasil. São Paulo: Fundação Perseu Abramo, 2005.

FONTES, Virginia. O Brasile o capital-imperialismo: teoria e história. Rio de Janeiro: UFRJ, 2010.

FUCKS, Werner. Ninguém é forte sozinho: um olhar sobre a missão da pastoral da terra. In: Saberes e olhares: a formação e a educação popular na Comissão Pastoral da Terra. São Paulo: Loyola, 2002. p. 53-68.

GERTZ, René. Os luteranos no Brasil. Revista de História Regional, v. 6, n.2, p. 9-33, 2001.

GIUMBELLI, Emerson. Religião e (des)ordem social: Contestado, Juazeiro e Canudos nos estudos sociológicos sobre movimentos religiosos. Dados, v. 40, n. 2, 1997.
GRAMSCI, Antônio. Cadernos do cárcere. Rio de Janeiro: Civilização Brasileira, 2007.

Os intelectuais e a organização da cultura. Rio de Janeiro: Civilização Brasileira, 1982.

HOLING, Paulo José. Sujeitos e práticas sociais: uma abordagem sobre a organização e resistência dos expropriados da Itaipu. In: XXVI SIMPÓSIO NACIONAL DE HISTÓRIA ANPUH. Anais... São Paulo, 2012. p. 1-12.

HUFF JÚNIOR, Arnaldo Érico. Um protestantismo protestante: Richard Shaull, missão e revolução. Tese (Doutorado em História Social) - Instituto de História, Universidade Federal do Rio de Janeiro, Rio de Janeiro, 2012. 267f.

LOWY, Michael. A guerra dos deuses: religião e política na América Latina. Petrópolis: Vozes, 2000.

MATTIELLO, Catiane; QUELUZ, Gilson Leandro. Narrativas de resistência: história oral de vida de famílias desapropriadas pela usina hidrelétrica de Itaipu. In: Histórica: Revista Eletrônica do Arquivo Público do Estado de São Paulo, n. 49, p. 1-1l, ago. 2011.

MAZZAROLLO, Juvêncio. A taipa da injustiça: esbanjamento econômico, drama social e holocausto ecológico em Itaipu. São Paulo: Loyola, 2003.

MENDONÇA, Sonia Regina. A classe dominante agrária: natureza e comportamento (1964-1990). São Paulo: Expressão Popular, 2006.

Estado e economia no Brasil: opções de desenvolvimento. Rio de Janeiro: Graal, 1986.

; FONTES, Virgínia. História e teoria política. In: CARDOSO, Ciro Flamarion Santana; VAINFAS, Ronaldo (Org.). Novos domínios da história. Rio de Janeiro: Elsevier, 2012. p. 55-71.

MEZZOMO, Frank. Memória dos movimentos sociais no oeste do Paraná: Gernote Kirinus, Adriano Van de Vem, Werner Fuchs. Campo Mourão: Fecilcam, 2009.

Pastor Werner Fuchs: uma biografia constituída numa práxis político-religiosa. Revista Alamedas, v. 1, n. 2, p. 1-8, 2006

MOTTA, Márcia Maria Menendes; ESTEVES, Carlos Leandro Silva. Ligas Camponesas: história de uma luta (des)conhecida. In: MOTTA, Márcia Maria Menendes; ZARTH, Paulo (Org.). Formas de resistência 
camponesa: visibilidade e diversidade de conflitos ao longo da história. Concepções de justiça e resistência nas repúblicas do passado (1930-1960). São Paulo: Unesp, 2009. v. 2, p. 243-257.

PAGE, Joseph. A revolução que nunca houve: o Nordeste do Brasil (1955-1964). Rio de Janeiro: Record, 1989.

PY, Fábio. Lauro Bretones: um protestante heterodoxo no Brasil de 1948 a 1956. Tese (Doutorado em Teologia) - Departamento de Pós-graduação em Teologia, Pontifícia Universidade Católica do Rio de Janeiro, Rio de Janeiro, 2016a. 267f.

The lutheran rebellion in the Brazilian Countryside. Crosscurrents, n. 12, p. 121-136, 2016 b.

RAMOS, Carolina. Capital e trabalho no sindicalismo rural brasileiro: um estudo acerca da CNA (Convenção Nacional da Agricultura) e da CONTAG (Convenção Nacional dos Trabalhadores na Agricultura). In: POLIS — LABORATÓRIO DE HISTÓRIA ECONÔMICOSOCIAL. Anais... Niterói: Universidade Federal Fluminense, 2010. p. 1-21.

RIBEIRO, Maria de Fátima Bento. Memórias do concreto: vozes na construção de Itaipu. Cascavel: Unioeste, 2002.

Itaipu, a dança das águas: histórias e memórias de 1966 a 1984. Campinas: Unicamp, 2006.
ROLLEMBERG, Denise. O apoio de Cuba à luta armada no Brasil. Rio de Janeiro: Mauad, 2001.

SCHWANTES, Milton. A teologia e o direito dos pobres. Entrevista com Schwantes concedida à Unisinos. 2011. Disponível em: 〈https://www.metodista.br/fateo/ noticias/duas-entrevistas-com-o-professor-miltonschwantes〉. Acesso em: 10 mar. 2014.

Estado e profecia: uma proposta para hermenêutica profética. Estudos Teológicos, v. 22, n. 2, 1982.

Projetos de esperanças: meditações sobre Gênesis 1-11. São Paulo: Paulinas, 2011.

STÉDILE, João Pedro (Org.). A questão agrária brasileira: história e natureza das Ligas Camponesas (1954-1964). São Paulo: Expressão Popular, 2006.

TARGINO, Ivan; MOREIRA, Emilia; MENEZES, Marilda. As Ligas Camponesas na Paraíba: um relato a partir da memória dos seus protagonistas. Ruris, v. 5, n. 1, p. 83-117, 2011.

VANDERLINDE, Tarcisio. Entre dois reinos: a inserção luterana entre os agricultores do Sul do Brasil. Tese (Doutorado em História Social) - Departamento de História. Universidade Federal Fluminense, Niterói, 2004. $462 f$. 